prostration, profuse cold sweat, slight dyspnoa and great restlessness. Temperature $101^{\circ}$; pulse 116. Ammonia was administered to the patient internally, and also applied externally to the swollen arm and bitten hand. The patient was delirious and passed an exceedingly restless night.

The following morning the arm and hand presented a phlegmonous erysipelatous appearance, with glandular enlargement and suppuration; dyspncea had increased; there was diarrhœe and an appearance of jaundice. Temperature $102^{\circ}$, pulse 122 .

During the following three days the patient's state was much the same as that on the day following his admission to the hospital. Ammonia and stimulants were continued.

On the fifth day the external aspects of the limb seemed to have improved, but high fever and restlessness continued. On feeling the arm I found that its entire length from the back of the hand to the shoulder was soft, and on making an incision above the wrist oozing matter ran from it abundantly. Similar incisions were made along the arm at three different places, the same kind of discharge made its appearance at all of them. Suppuration and sloughing continued for several days, during which antiseptic dressing was nsed. On July 22 nd the patient had quite recovered with the exception that his arm and fingers were rather stiff.

Larnaca.

\section{ON THE USE OF A NEW SILVER SALT IN THE TREATMENT OF ORGANIC NERVOUS DISEASE.}

BY ALLAN M. LANE HAMILTON, M.D.,

ONE OF THE CONSULTING PHYSTCIANS TO THE NEW YORK CITY INSANE ASYLUMS, AND TO THE HOSPITAL FOR NERVOUS DISEASES, BLACKWELL'S ISLAND, N.Y.

I HAVE no doubt my own disappointment in the use of various remedies recommended by different authorities for the treatment of organic nervous disease is shared by many who have given even the most promising a fair trial. Nitrate of silver, a drug with an ancient reputation, is one of the few not to be despised, for occasionally it proves of great service, but, as a rule, it is entirely inefficacious. We are, therefore, too apt, in a great majority of instances, to resort in a routine way to iodide of potassium, or mercurial treatment, with variable results.

About three years ago it occurred to me that the com. bination of phosphorus with silver might well be worth trying. I therefore, through the kindness of Dr. Doremus of Buffalo, procured a sample of the tribasic phosphate of silver, a salt prepared in the following manner :-Precipitate a solution of argentic nitrate with a solution of trisodic orthophosphate, wash with distilled water, and dry in the dark. The process may be expressed as follows :- $3 \mathrm{NO}_{3} \mathrm{Ag}+$ $\mathrm{PO}_{4} \mathrm{Na}_{3}, 12 \mathrm{H}_{2} \mathrm{O}=\mathrm{Ag}_{3} \mathrm{PO}_{4}+3 \mathrm{NaNO}_{3}+12 \mathrm{H}_{2} \mathrm{O}, \mathrm{Ag}_{3}, \mathrm{PO}_{4}$.

A second sample of the drug was made by Mr. Frazer, of Caswell, Hazard, and Co., New York, according to the above formula. It was a heavy powder of a lemon-yellow colour, and was slightly darkened by exposure to the light.

The tribasic phosphate of silver possesses advantages over the other silver salts which entitle it to a fair trial. I have given it for months in doses varying from one-third to half a grain without any skin discoloration whatever, and its administration is unattended by the gastric irritability that so often follows the use of either the nitrate of silver or the phosphide of zinc. At the same time its therapeutical effects are much more pronounced. It is best given with some such excipients as argol and glycerine, for vegetable substances tend to decomposition; and for this reason I have discarded the confection of roses as an element of the pill mass.

In the first edition of my work upon Nervous Diseases ${ }^{1} I$ directed attention to the probable advantages of this drug, especially in sclerosis of the posterior columns. The experience of two years has convinced me that it is my duty to urge others to make use of the remedy. In two class of cases it has proved to be of great value-1. In those of more or less acute myelitis with disturbance of the bladder and rectum. Not only in such cases of transverse disease has there been a decided improvement in the matter of control over the func- tions of these organs, but there has been a decided gain in the muscular power. This has been conspicuous in a very remarkable case of chronic meningo-myelitis seen in consul. tation with Dr. Todd of Ridgefield, Conn. 2. In cases of sclerosis of the nervous substance. In seven cases of posterior spinal sclerosis there has been a subsidence more or less in the violence of the pains, and in those who have taken the drug for over a year the power of locomotion is materially increased.

In six cases of inveterate epilepsy, as the result of gross inflammatory intracranial changes, the patients have been relieved, judging from the diminution in the number of the attacks.

I am now giving the drug to patients with cerebral tumour and general paralysis, and while it would be out of the question to expect anything like permanent cure in such hopeless diseases, I do believe that a persistent and proper use of the silver salt will do much more for the patients than any of the drugs hitherto used. I can find in medical literature no record of the use of the phosphate of silver, nor am $I$ able to learn by inquiry that it was used prior to 1878. I sincerely hope that others may be prompted to publish their experience.

East 33rd Street, New York.

\section{A : athitrot}

\section{HOSPITAL PRACTICE, BRITISH AND FOREIGN.}

Nulla autem est alia pro certo noscendi vaa, nisi quamplurimas et morborum et dissectiorum historias, tum aliorum tum proprias collectas habere, $\theta$ inter se comparare.-Morgagri De Sed. et Caua. Morb., lib.iv. Procomium.

\section{MIDDLESEX HOSPITAL}

HYSTERICAL VOMITING OF EIGHT MONTHS' DURATION.

\section{(Under the care of Dr. Coupland.)}

THE following summary may be of interest in connexion with the case read by Dr. Sutherland at the last meeting of the Clinical Srciety :-

Bridget $\mathbf{S}$ - aged twenty-four, a domestic servant, unmarried, was admitted on May 2nd, 1879, under Dr. Greenhow, and subsequently came under the care of Dr. Coupland. She had never been ill before, was habitually constipated, but menstruated regularly. Seven months before admission she was attacked with giddiness, faintness, and vomiting after food; she did not bring up blood at this time, but she stated that six weeks later bright blood was vomited. From that time vomiting had continued at intervals, and she suffered from continuous pain at the pit of the stomach, periodically worse every three weeks. Vomiting, which ensued immediately on taking food, always relieved the pain. The patient's appearance was certainly not that of one suffering from organic disease. She was pale, stout, and flabby, and although at first apparently suffering pain, her expression was for the most part calm and placid, and even apathetic The pain she complained of was seated between the shoulders and in the epigastrium; there was limited tenderness in the latter region, where pressure also excited dorsal pain. Tongue was clean; bowels constipated. No other organs objectively deranged. Temperature $98.5^{\circ}$, pulse 88 , full and regular. Urine, sp. gr. 1025, acid, no albumen. Before the evening she had vomited a large quantity of greenish fluid, neutral in reaction, containing bile. It may be added that the vomited matter was always of this character, clear (un. less mixed with curdled milk or other ingesta), and of a grass-green tint, sometimes assuming an olive colour after long exposure. The vomiting proved to be the predominant symptom, recurring several times a day, but the pain and tenderaess varied in intensity, in duration, and in situation. Sometimes there was nausea with or without vomiting, and very frequent attempts at vomiting. On the 20th of May Dr. Hall Davis was consulted, but the greatly contracted hymen prevented uterine examination, nor was there any reason for suspecting uterine derangement.

On admission she was put upon a diet restricted to jelly, beef-tea, and three pints of milk, all solid food being inter. 